\title{
AVALIAÇÃO DA APRENDIZAGEM: UMA REFLEXÃO TEÓRICA MEDIANTE AS PRÁTICAS ENCONTRADAS NUMA ESCOLA CAPIXABA \\ http://dx.doi.org/10.5902/2318133855358
}

\author{
Izadora Pedruzzi ${ }^{1}$ \\ Karine Silveira ${ }^{2}$
}

\begin{abstract}
Resumo
É reconhecidamente importante refletir acerca da avaliação da aprendizagem, visto que é parte importante dos processos de ensino e aprendizagem. Por isso tratamos acerca das práticas avaliativas ocorridas na disciplina de Língua Portuguesa numa escola estadual do Espírito Santo. A instituição foi escolhida devido a pontuação na avaliação do Programa de Avaliação da Educação Básica do Espírito Santo ter sido acima da nota de toda a rede estadual. A interpretação dos dados obtidos foi realizada com base nos estudos de Carminatti e Borges (2012), Fidalgo (2006), Hoffman (2011) e Luckesi (2000).

Palavras-chave: avaliação; aprendizagem; ensino.
\end{abstract}

\section{LEARNING EVALUATION: A THEORETICAL REFLECTION THROUGH THE PRACTICES FOUND IN A BRAZILIAN SCHOOL}

\begin{abstract}
It is increasingly necessary to reflect on the assessment of learning since it is an important part of the teaching-learning process. Therefore, in this study, we deal with the evaluative practices that took place in the Portuguese language discipline of a state school in Espírito Santo. The school was chosen because the score in the evaluation of Basic Education Evaluation Program of Espírito Santo was above the grade of the entire state network. The data interpretation was based on the studies by Carminatti and Borges (2012), Fidalgo (2006), Hoffman (2011), and Luckesi (2000). Key-words: evaluation; learning; teaching.
\end{abstract}

\footnotetext{
${ }^{1}$ Instituto Federal de Educação, Ciência e Tecnologia do Espírito Santo, Brasil. E-mail: izapedruzzi@hotmail.com. 2 Instituto Federal de Educação, Ciência e Tecnologia do Espírito Santo, Brasil. E-mail: karine.silveira@ifes.edu.br. Regae: Rev. Gest. Aval. Educ. Santa Maria v. 10 n. 19 e55358, p. 1-11 2021
} 


\section{Introdução}

avaliação da aprendizagem é tópico para diversas discussões e pesquisas,
seja no ensino básico ou superior, e está presente nas aulas de didática, nos
cursos de licenciatura e nas formações continuadas oferecidas a diversos docentes que já exercem a profissão. Devido às falhas no processo de avaliação que encontramos hoje no ensino, dentre elas o uso classificatório da nota obtida e a dicotomia existente entre o momento de ensinar e o momento de avaliar, tratar sobre essa temática tornou-se fundamental para a melhoria da educação.

Portanto, a fim de refletirmos sobre 0 ato de avaliar presente nas práticas educacionais, optamos por conhecer essas práticas em uma escola estadual de ensino médio localizada em Vargem Alta, região serrana do Espírito Santo, no final do segundo semestre de 2018, momento em que ocorreram as avaliações finais e reuniões pedagógicas para se discutir o rendimento dos estudantes. A escola que nos proporcionou esse momento de diálogo e aprendizagem, por meio de conversas informais com a equipe, foi selecionada devido à experiência da autora do artigo em ter sido aluna dessa instituição e por essa escola ter sua pontuação na avaliação do Programa de Avaliação da Educação Básica do Espírito Santo - Paebes - acima da nota de toda a rede estadual. Destacamos aqui que a média da escola na disciplina de Língua Portuguesa para a $3^{\circ}$ série do ensino médio no período de 2015 a 2018 foi de 307,42 e a média estadual no mesmo período foi de 281,6. Além disso, é importante destacar que os docentes participantes eram, no momento da coleta de dados, os únicos que lecionavam a disciplina de Língua Portuguesa na escola, por isso apresentamos paráfrases de apenas dois relatos. A escolha da disciplina de Língua Portuguesa ocorreu devido à área de atuação das autoras do artigo.

É relevante destacar que este estudo pauta-se, principalmente, na concepção de avaliação proposta por Hoffman (2011), em que a avaliação seria mediadora dos processos de ensino e aprendizagem, visto que representaria a reflexão que se transforma em ação, permitindo ao educador refletir sobre sua própria realidade bem como a de seus estudantes, acompanhando o passo a passo na construção do conhecimento; e na concepção proposta por Luckesi (2000), considerando a avaliação um processo amoroso, inclusivo, dinâmico e construtivo, que acolhe o educando. Com o objetivo de estimular uma mudança de abordagem da avaliação da aprendizagem, buscamos defender o modelo mediador e acolhedor nas práticas avaliativas.

\section{$O$ ato de avaliar}

Acreditamos que 0 ato de avaliar deve ser parte integrante e constituitiva do processo de ensino, e não um meio de punir e classificar os estudantes, de dizer quem obteve sucesso e quem fracassou. Devido a isso torna-se necessário refletir sobre a avaliação da aprendizagem utilizada na escola, uma vez que compõe parte importante dos processos de ensino e aprendizagem. Por isso, com o intuito de fundamentar as reflexões acerca das práticas avaliativas ocorridas na disciplina de Língua Portuguesa na escola participante do estudo, tecemos algumas considerações que a teoria apresenta sobre o tema da avaliação da aprendizagem. Para tanto, principalmente Hoffman (2011) e Luckesi (2000) fundamentaram e guiaram nossas análises. 
Segundo Carminatti e Borges (2012), "a avaliação não pode ser tratada de forma isolada" (p. 167), uma vez que envolve todo o fazer pedagógico, sendo necessário, portanto, compreender que $\mathrm{o}$ ato avaliativo está imerso em todos os momentos da prática educativa. Atualmente, entretanto, 0 ato de avaliar se configura em um modelo reducionista, que o limita a apenas classificar os estudantes mediante sua desenvoltura no processo de ensino, não sendo, portanto, parte integrante da aquisição do conhecimento. As autoras alertam que "o processo avaliativo é colocado como produto final de todo grande processo educacional, sem reflexões, totalmente à parte" (p. 175), sendo, de tal forma, apenas o responsável por mensurar o quanto o estudante aprendeu ou não ao longo de um dado tempo de estudos, sem quaisquer fins que oportunizem a evolução da aprendizagem desse discente.

Essas características expostas por Carminatti e Borges (2012) condizem com o modelo de avaliação pautado no ensino bancário. Para esse modelo o professor depositaria seus conhecimentos no estudante e, ao fim do período de estudos, retira o extrato, que seria a nota da avaliação aplicada. Para Fidalgo (2006) "avaliação e testagem passam a ser conceitos sinônimos, uma vez que, tendo como meta a devolução objetiva dos conhecimentos depositados, a prova seria o único instrumento utilizado para a ampla tarefa de avaliar" (p. 19), sem qualquer criticidade ou interferência por parte do estudante. Nota-se que essa concepção reduz o processo de avaliação à tarefa de mensurar o que o estudante teria ou não aprendido, em nada contribuindo para o processo de aprendizagem em si, uma vez que representa um processo final que apenas atribui uma nota ao estudante.

Fazendo uso desse modelo de avaliação bancária o docente aceita e reforça o "abusivo uso das notas, sem percebê-lo como um mecanismo privilegiado de competição e seleção nas escolas" (Hoffman, 2011, p. 45). Como alerta Luckesi (2000), a "avaliação da aprendizagem não é e não pode continuar sendo a tirana da prática educativa, que ameaça e submete a todos" (p. 1). Entretanto, não se pode ocultar o fato de que essa concepção equivocada do ato avaliativo é antiga, possuindo embasamento nos primórdios da organização escolar. Desta forma, nota-se que ainda que 0 ato avaliativo tenha evoluído, muito do que fora no passado se faz presente entre as práticas avaliativas atuais. Isso possivelmente acontece devido à grande defasagem no contato dos professores com a avaliação mediadora e acolhedora. Uma provável falta de conhecimento e de domínio de teorias que defendem uma nova forma de avaliar a aprendizagem faz com que, consequentemente, esse ensino bancário permaneça presente nas salas de aula.

Carminatti e Borges (2012) afirmam que a avaliação "deve oportunizar um momento de aprendizagem, desconstruindo os mitos que historicamente foram acumulados pela sociedade escolar" (p. 176). Com isso "a avaliação deixa de ser um momento terminal do processo educativo [...] para se transformar na busca incessante de compreensão das dificuldades do educando e na dinamização de novas oportunidade de conhecimento" (Hoffman, 2011, p. 19).

Ademais, destacamos as concepções avaliativas defendidas por Hoffman (2011) e Luckesi (2000) que norteiam as reflexões propostas nesse trabalho. Hoffman (2011) defende a "perspectiva da ação avaliativa como uma das mediações pela qual se encorajaria a reorganização do saber" (p. 57), ou seja, pela avaliação constante do

\begin{tabular}{|l|l|l|l|l|l|}
\hline Regae: Rev. Gest. Aval. Educ. & Santa Maria & v. 10 & n. 19 & e55358, p. 1-11 & 2021
\end{tabular}


processo de ensino, professores e estudantes teriam a possibilidade de pensar e repensar o fazer educacional, aproveitando a prática avaliativa ao longo da busca pelo aprendizado. Para Luckesi (2000) a avaliação da aprendizagem é um "recurso pedagógico útil e necessário para auxiliar cada educador e cada educando na busca e na construção de si mesmo e do seu melhor modo de ser na vida" (p. 1), lidando com a avaliação de modo amoroso, acolhedor, encarando-a como um instrumento que aproxima o estudante do professor; nessa perspectiva, a avaliação acolhe o educando, diagnostica aquilo que precisa ser melhorado e permite ao docente decidir o que fazer a partir do dado obtido, sendo também parte integrante e indispensável do processo de ensino.

Com o intuito de, enfim, refletir sobre a avaliação da aprendizagem na prática escolar, faz-se necessária a compreensão da realidade vivenciada pelos docentes. Como afirma Hoffman (2011) "é a partir da análise de situações vividas pelos professores no seu cotidiano, [...], que poderemos avaliá-los a reconduzir suas ações e compreendê-las numa outra perspectiva" (p. 16).

\section{Metodologia}

O presente estudo foi desenvolvido a partir de uma entrevista semiestruturada. Foi elaborado um conjunto de questões previamente definidas, mas as propôs em um contexto muito semelhante ao de uma conversa informal, a qual foi realizada na biblioteca da instituição. Os funcionários que estavam presentes, no ambiente da conversa, eram apenas os docentes que responderiam ao questionário, o que os deixou à vontade para relatarem a realidade vivida por eles sem a tensão da presença de um gestor. Ademais, o encontro foi realizado no horário de planejamento dos entrevistados, a fim de que nenhuma de suas aulas fossem interrompidas, deixando-os despreocupados, por consequência, quanto ao tempo gasto para exposição dos relatos.

As perguntas foram direcionadas aos professores e os apontamentos foram registrados em anotações feitas para análises posteriores. Os dados recolhidos se referiam às experiências dos docentes com a avaliação da aprendizagem e aos resultados obtidos pelos estudantes ao longo do ano de 2018, sendo analisados a partir da teoria da avaliação da aprendizagem escolhida para estudo.

Destacamos, ainda, que o questionário proposto para auxiliar na conversa com os docentes serviu como orientação, não sendo seguida, necessariamente, a ordem das questões exposta abaixo.

Quadro 1 -

Questões e objetivos.

\begin{tabular}{|c|c|}
\hline Questionário elaborado & Objet \\
\hline $\begin{array}{l}1 \text { - Durante a sua formação em } \\
\text { você teve alguma disciplina sobre } \\
\text { "Avaliação da Aprendizagem"? S } \\
\text { qual? E o que se lembra de ter es } \\
\text { na época? }\end{array}$ & $\begin{array}{l}\text { pelos professores sobre a avaliação da } \\
\text { aprendizagem, além de verificar se o tema } \\
\text { foi contemplado no plano de curso da } \\
\text { licenciatura feita por ambos. }\end{array}$ \\
\hline $\begin{array}{l}2-\text { Hoje, com a sua experiência } \\
\text { profissional, o que você pode falar sobre a } \\
\text { avaliação da aprendizagem? O que ela era }\end{array}$ & $\begin{array}{l}\text { Compreender algumas de suas opiniões } \\
\text { sobre a prática de avaliar, além de } \\
\text { constatar se, com a experiência adquirida } \\
\text { ao longo dos anos na profissão, tais }\end{array}$ \\
\hline
\end{tabular}

Regae: Rev. Gest. Aval. Educ. $\quad$ Santa Maria

v. 10

ก. 19

e55358, p. 1-11

2021 


\begin{tabular}{|c|c|}
\hline & $\begin{array}{l}\text { opiniões evoluíram ou permaneceram as } \\
\text { mesmas. }\end{array}$ \\
\hline $\begin{array}{l}3 \text { - Ao longo do ano letivo, como você } \\
\text { planeja, desenvolve e quais instrumentos } \\
\text { utiliza para avaliar a aprendizagem de } \\
\text { seus discentes? }\end{array}$ & $\begin{array}{l}\text { Conhecer as práticas utilizadas pelos } \\
\text { docentes, além de investigar a forma com } \\
\text { que organizam a avaliação da } \\
\text { aprendizagem durante o ano letivo. }\end{array}$ \\
\hline $\begin{array}{l}4 \text { - Quanto às provas diagnósticas: são } \\
\text { desenvolvidas? Como funcionam? }\end{array}$ & $\begin{array}{l}\text { Compreender se fazem uso ou não desta } \\
\text { prática avaliativa. }\end{array}$ \\
\hline $\begin{array}{l}5 \text { - Após a aplicação de um instrumento } \\
\text { avaliativo, quais atitudes você toma? }\end{array}$ & $\begin{array}{l}\text { Investigar se a avaliação da } \\
\text { aprendizagem proporciona atitudes } \\
\text { posteriores, que possibilitam o avanço do } \\
\text { conhecimento, ou se ela se encerra na } \\
\text { constatação da nota. }\end{array}$ \\
\hline $\begin{array}{l}6 \text { - Com qual prática avaliativa vocês } \\
\text { acreditam que os discentes aprendam } \\
\text { mais: provas, trabalhos, seminários, listas } \\
\text { etc.? }\end{array}$ & $\begin{array}{l}\text { Investigar as preferências dos docentes } \\
\text { quanto às práticas e metodologias } \\
\text { existentes na avaliação da aprendizagem. }\end{array}$ \\
\hline $\begin{array}{l}7 \text { - Você classificaria a sua metodologia de } \\
\text { ensino como: tradicional, construtivista ou } \\
\text { Sócio-interacionista? Ou alguma outra? } \\
\text { Justifique. }\end{array}$ & $\begin{array}{l}\text { Compreender a forma com que eles } \\
\text { próprios encaram suas respectivas práticas. }\end{array}$ \\
\hline $\begin{array}{l}8 \text { - Quantos discentes iniciaram o ano? } \\
\text { Quantos eram repetentes? Hoje, quantos } \\
\text { foram aprovados? Os repetentes } \\
\text { conseguiram aprovação? Repetentes } \\
\text { reprovaram de novo? E o que vocês } \\
\text { pensam dessas reprovações? }\end{array}$ & $\begin{array}{l}\text { Mensurar os resultados obtidos pelos } \\
\text { estudantes e compreender a opinião dos } \\
\text { professores mediante eles. }\end{array}$ \\
\hline
\end{tabular}

Fonte: autoras.

O compartilhamento das experiências vividas pelos docentes ocorreu, portanto, de maneira leve, pautado em uma troca de experiências agradável e construtiva, o que possibilitou que os participantes se sentissem confortáveis para conversarem sobre os temas propostos no quadro 1. Dessa maneira, tornou-se possível a reflexão e interpretação da realidade relatada pelos professores referente às práticas avaliativas realizadas por eles.

\section{Uma reflexão teórica mediante a realidade encontrada}

Optou-se por realizar a visita na escola no final do ano letivo de 2018, a fim de recolher dados que se referissem não apenas à avaliação da aprendizagem, mas também aos resultados obtidos pelos estudantes ao longo do ano escolar. Desta forma, no dia 5 de dezembro de 2018 os dois docentes participantes se dispuseram a conversar sobre 0 questionário previamente elaborado.

É válido evidenciar que a escola escolhida para pesquisa localiza-se no interior do Estado do Espírito Santo, sendo sediada em prédio compartilhado com a escola municipal da região. A instituição conta com poucas salas disponíveis para uso dos estudantes e professores do ensino médio, além do grande número de estudantes numa mesma turma 
e poucos materiais à disposição para serem utilizados. Compreende-se, diante dessa situação, a complexidade de se encontrar metodologias que fujam ao tradicional, o qual muitos já encontram-se adaptados e acomodados.

Ao serem questionados se, durante a graduação em Letras, cursaram alguma disciplina que abordasse o tema 'avaliação da aprendizagem' ambos concordaram que não estudaram sobre o assunto e ainda ressaltaram que pouco do que foi visto durante 0 curso se relacionou de fato com a prática docente. Explicam que cursaram matérias de didática, mas que elas não possuíam nenhum vínculo com a realidade vivida nas escolas e, além disso, não apresentavam nada que envolvesse o tema avaliação.

Portanto, devido ao pouco conhecimento teórico na área de avaliação da aprendizagem por parte dos docentes, como exposto acima, a prática avaliativa dos professores embasa-se em experiências pessoais, vivenciadas quando ainda eram estudantes. Dessa forma, a concepção de avaliação pautada apenas na classificação dos discentes, com fortes características tradicionais, perpetua-se.

No que diz respeito à forma com que compreendiam a avaliação da aprendizagem, no início de suas carreiras, os professores foram unânimes em suas respostas. 0 professor A afirmou que acreditava que a avaliação da aprendizagem fosse apenas preparar uma prova, aplicá-la e corrigi-la. O professor B concordou com o apontamento do colega e acrescentou que percebia todo o processo de avaliação da aprendizagem de forma muito conteudista, ou seja, o ato de avaliar resumia-se a testes que, por sua vez, eram aplicados para medição do quanto o estudante absorveu ou não do conteúdo ensinado.

Entretanto, após anos exercendo a profissão ambos os entrevistados percebem que, em certos casos, é preciso adaptar a avaliação às turmas e a determinados estudantes. Isso aponta que, com a prática, os docentes observaram que a avaliação precisa de se adequar à realidade de cada turma, de cada estudante. Apesar disso os professores apontaram alguns problemas que circundam o universo da avaliação da aprendizagem, sendo um deles a influência excessiva do governo no que diz respeito aos métodos avaliativos. Conforme os docentes a avaliação da aprendizagem é planejada a partir de um cronograma que recebem pronto da superintendência, o qual contém as divisões das notas que serão atribuídas a cada atividade - prova, trabalho, qualitativa - para que se some a nota final do trimestre. Isso, segundo eles, limita os meios para se avaliar o estudante.

Um segundo problema apontado pelos docentes seria a importância atribuída às provas nacionais e estaduais, como Enem e Paebes. Reforçam que não negam a necessidade de se trabalhar de maneira voltada a estes instrumentos avaliativos, já que os estudantes terão que passar por eles ao longo de sua jornada escolar, mas criticam a limitação que impõem às suas respectivas práticas docentes. Isso faz com que os docentes tenham que adaptar boa parte de suas aulas, dando foco a essas avaliações de larga escala.

Ainda sobre as avaliações de âmbito nacional e estadual os professores também demonstraram insatisfação na forma com que são elaboradas, por estarem em desacordo com a realidade de aprendizagem dos estudantes, não exigindo o conhecimento que é abordado em sala de aula. Luckesi (2000) trata sobre o assunto e alerta que "a avaliação não pode assentar-se sobre dados secundários do ensino-aprendizagem, mas, sim, sobre

\begin{tabular}{|l|l|l|l|l|l|}
\hline Regae: Rev. Gest. Aval. Educ. & Santa Maria & v. 10 & n. 19 & e55358, p. 1-11 & 2021 \\
\hline
\end{tabular}


os que efetivamente configuram a conduta ensinada e aprendida pelo educando" (p. 4). É necessário, portanto, avaliar o que realmente foi apresentado ao estudante em sua trajetória de aprendizado.

Pontuam ainda outras falhas no processo de avaliação da aprendizagem, como as recuperações que, obrigatoriamente, precisam ser aplicadas aos estudantes que não atingem a nota após cada atividade avaliativa. Tal fato, segundo eles, ocasiona o descuido e o desinteresse por parte dos estudantes, por sempre poderem contar com esta segunda chance. Além disso, os docentes demonstram insatisfação quanto às provas qualitativas, que proporcionam uma nota consideravelmente simples de ser conquistada.

Com relação ao terceiro ponto da entrevista, que questiona os professores sobre como planejam, desenvolvem e quais instrumentos utilizam para avaliar a aprendizagem, foi explicado que buscam seguir as exigências do governo, fazendo uso das práticas previstas no cronograma pré-montado que recebem. Assim, desenvolvem com os estudantes trabalhos diversos, como apresentações e pesquisas; avaliam o caderno, observando os vistos dados nas atividades feitas ao longo do trimestre; pontuam o comportamento dos estudantes, pela avaliação qualitativa; aplicam a costumeira prova, que mede o quanto foi apreendido pelo estudante, além de somar à nota final o resultado obtido no Paebes, que é elaborado e corrigido pelo governo.

Quanto à pergunta quatro da entrevista, referente às provas diagnósticas, ambos os profissionais relataram que, aos primeiros anos, é direcionado um teste para nivelamento de ensino, a fim de que os professores das matérias de Língua Portuguesa e Matemática compreendam o nível de conhecimento em que os estudantes ingressantes no ensino médio se enquadram. No entanto, as provas são encaminhadas prontas pelo governo, sem que haja um prévio conhecimento da turma para um melhor entendimento do que deve ser abordado, comprometendo, de tal modo, os resultados obtidos.

Luckesi (2000) alerta sobre os perigos dos meios equivocados utilizados para a obtenção de dados na avaliação da aprendizagem. Afirma que qualquer instrumento avaliativo defeituoso pode obter resultados distorcidos, fazendo com que as informações encontradas não se equiparem à realidade da turma. Devido a esse risco faz-se preciso desenvolver as próprias avaliações diagnósticas, sanando o problema enfrentado, aplicando não apenas a prova entregue pronta pela superintendência, mas outra, pensada e elaborada pelo professor, desenvolvida a partir do acolhimento da turma recém-chegada, feita através de conversas e observações. Com isso, o diagnóstico se tornaria justo perante os estudantes.

Além disso é interessante observar que os professores trataram apenas sobre a prova diagnóstica aplicada às turmas ingressantes no ensino médio, dando a entender que, nos demais níveis, esta sondagem inicial não é realizada. Dessa forma é válido ressaltar a importância de a prova diagnóstica ser desenvolvida não apenas nos primeiros anos, mas em todas as turmas, já que proporciona um momento de contato com a situação real a que se encontra a sala e cada discente, individualmente, sendo uma prática indispensável para norteamento dos trabalhos desenvolvidos pelo docente no início do ano letivo. 
Em seguida conversamos sobre quais atitudes eram tomadas após a aplicação de um instrumento avaliativo. Ambos disseram que a avaliação se encerra na prova, sendo aplicada apenas a recuperação aos que precisam, antes de seguirem para um novo tema. O professor $\mathrm{A}$ acrescentou que não há tempo para trabalhar mais o conteúdo, já que é necessário que todos os assuntos programados sejam abordados até o fim do ano letivo e, caso se atenham demais em um só tópico, terão que deixar de ensinar outros. $O$ professor B também ressaltou que, caso se estendam em um assunto e proponham atividades diferenciadas, os educandos demonstram certa insatisfação. Por isso, optam por finalizar o ciclo de aprendizagem de um tema trabalhado após a aplicação da prova.

Tal fato confirma o que Hoffman (2011) aponta como a concepção da avaliação da aprendizagem atual, que perpassa o processo de ensino de educandos e educadores de todo o país, sendo o ato de avaliar apenas um julgamento de valor, uma etapa terminal, marcada pelo registro, classificação e seleção dos estudantes. Como alerta a pesquisadora, "os educadores percebem a ação de educar e a ação de avaliar como dois momentos distintos e não relacionados" (p. 15), transformando, por conseguinte, o fazer avaliativo em um fragmento desconexo do momento de aprendizagem, em que apenas a nota obtida importa, deixando de lado o que realmente foi ou não apreendido pelo estudante.

Para Carminatti e Borges (2012) a educação atual possui o desafio de superar as crenças trazidas dentre as gerações pela ressignificação da avaliação da aprendizagem. Tal ressignificação surgiria a partir da compreensão da importância de um fazer avaliativo orientador, que ultrapassa o modelo reducionista, tornando a avaliação parte integrante e fundamental do processo de ensino como um todo.

$\mathrm{Na}$ busca da superação de tais práticas que subjugam a avaliação da aprendizagem atualmente torna-se necessário incitar mudanças em questões como a descrita acima, em que $o$ ato avaliativo encerra-se na prova. Afinal, como defende Luckesi (2000), o ato de avaliar não pode ter fim na simples constatação dos resultados, ou seja, no registro das notas dos estudantes, já que é "um ato dinâmico, que implica na decisão de o que fazer. Sem este ato de decidir, o ato de avaliar não se completa. Ele não se realiza" (p. 3). Por isso seria necessário desconstruir o ideal tradicional da avaliação que tem fim em si mesma e ressaltar a importância de partir dos resultados obtidos com o ato de avaliar para a evolução dos conhecimentos construídos pelos discentes.

Ao longo da entrevista os docentes também foram questionados sobre qual método de avaliação seria mais válido para a aprendizagem do estudante. Mais uma vez concordaram em afirmar que a prova é o melhor dos meios. Segundo eles, em apresentações ou pesquisas, por exemplo, o estudante desinteressado consegue se esquivar com mais facilidade de suas responsabilidades, deixando para que os colegas desenvolvam a atividade. Quando é submetido a uma prova, no entanto, sua nota depende apenas de si mesmo, fazendo com que não haja outra saída a não ser realmente estudar.

Hoffman (2011) explica que o teste serve para o docente como um instrumento investigativo a fim de compreender o estágio de construção do conhecimento do estudante, com o intuito de, em seguida, melhor orientá-lo no caminho do aprendizado. A 
utilização de provas, portanto, não pode ser encarada como um problema. Todavia, faz-se necessária a desconstrução do ideal de que 0 ato de avaliar precisa, necessariamente, estar vinculado à aplicação de testes para a garantia de sua eficiência.

Sabemos que ambos os profissionais não detêm suas práticas avaliativas apenas às provas, uma vez que explicaram durante a conversa que fazem uso de apresentações, pesquisas e outros métodos para compor a nota trimestral. Torna-se importante, entretanto, observar a opinião dos mesmos de que os testes contribuem mais para a aprendizagem do estudante que outros métodos avaliativos, a fim de identificar nesta resposta o aspecto tradicional que permeia suas práticas.

Ao final da entrevista, quando questionados sobre como classificariam suas respectivas metodologias de ensino, ambos responderam que se identificam com a tradicional. Ressaltam, mais uma vez, que o tempo acaba por limitar os meios que buscam para avaliar os estudantes, já que atividades diferenciadas demandam mais aulas para organização; e afirmam ser complicado se afastar do tradicional, já que os próprios discentes cobram essa metodologia de ensino.

O fato de que os estudantes acabam por requerer as práticas tradicionais de avaliação se explica, possivelmente, pela falta de contato com outras técnicas inovadoras, sendo, portanto, privados da experiência de viver a avaliação da aprendizagem em seu sentido mediador e acolhedor - tal qual provavelmente acontecera com os professores participantes, quando ainda eram estudantes.

Ressaltamos que, mesmo enfrentando limitações, os docentes A e B entendem a necessidade de avaliar os processos de ensino e aprendizagem e tentam lidar da melhor forma possível com as dificuldades encontradas. Porém, pela provável falta de conhecimento de outras práticas avaliativas, torna-se ainda mais difícil a busca pela evolução dos usos da avaliação no ensino. Dessa forma é necessário o incentivo ao contato com metodologias de avaliação que prezem pela construção do saber do estudante e auxiliam ao longo de todo o processo de ensino.

Por fim, para encerrar a entrevista, foi pedido que fizessem uma breve avaliação dos resultados obtidos ao longo do ano letivo, principalmente com relação aos estudantes que foram reprovados no ano anterior. Os profissionais afirmaram que havia poucos estudantes repetentes e que a grande maioria deles conseguiu ser aprovado ao cursar o ano pela segunda vez. Explicam que alguns acabaram por se afastar da escola pela transferência ou abandono, ou se mantiveram desinteressados, mas reforçam que esta quantidade é inferior aos que encararam a reprovação como uma lição positiva e mudaram seus hábitos de estudo, empenhando-se mais e, consequentemente, melhorando suas notas.

Nota-se que os professores percebiam a reprovação como uma forma de punição cujas consequências seriam positivas ou negativas. Alguns discentes, segundo os professores, consideram a reprovação algo bom, pois a utilizam como incentivo para a mudança de suas atitudes. No entanto, há educandos que não se adaptam bem à situação e acabam por serem excluídos dos processos de ensino e aprendizagem, evadindo. Tal qual aponta Luckesi (2000), as ações avaliativas pautadas em exames, com características tradicionalistas e bancárias, selecionam, excluem, marginalizam; diferentemente da concepção de avaliação acolhedora e mediadora, que "inclui, traz para dentro" (p. 1). 
É importante ressaltar que a avaliação acolhedora, contudo, não aceita tudo o que parte do educando como correto, tal qual expõe Luckesi (2000). Ela permite a relação direta entre docente e discente, considerando como natural todo e qualquer confronto, que poderá ser de negociação, redirecionamento ou aceitação. Diante disso, baseados nessa concepção de avaliação acolhedora, não estamos aqui defendendo que o estudante não seja reprovado, mas se os responsáveis pelo processo de avaliação da aprendizagem revissem suas práticas, pudessem discutir sobre essa temática, tivessem maior liberdade no planejamento das ações seria possível mostrar ao estudante que a reprovação torna-se algo necessário para sua própria evolução do conhecimento, reduzindo, desta maneira, o número de evasões de repetentes nas diversas escolas do país.

\section{Considerações finais}

Nota-se que, por detrás das práticas avaliativas dos profissionais entrevistados, existem marcas da concepção de avaliação bancária da aprendizagem (Fidalgo, 2006), com características tradicionais, muito relacionadas ao exame e ao simples registro de notas. Entende-se, todavia, que a justificativa para tal fato seria a ausência de contato com teorias que defendem um fazer avaliativo mediador, integrante do processo de ensino.

A partir dessa defasagem no acesso à concepção mediadora do ato de avaliar, torna-se possível compreender a necessidade da oferta de disciplinas que tratem sobre a avaliação ainda em meio aos cursos de licenciatura, a fim de tornar possível o contato diversificado com o tema. Dessa forma futuros professores têm a possibilidade de conhecer novas práticas e filosofias do processo avaliativo, chegando às salas de aula com o entendimento de que, como explica Luckesi (2000), a avaliação possui diversos propósitos, dentre eles o de acolher o estudante, diagnosticar a situação encontrada em cada caso e decidir como melhorar o processo ensino-aprendizagem.

Apesar disso sabemos que muitas das licenciaturas ofertadas por diversas instituições de ensino superior não contam com a matéria de avaliação da aprendizagem, como é o caso da formação feita pelos professores entrevistados e de tantos outros docentes que já se encontram em meio ao magistério. Com o intuito de solucionar esta defasagem encontrada mesmo após anos exercendo a profissão, propõem-se a busca e renovação de conhecimentos.

Proporcionar contato com teorias que façam com que os docentes entendam que "a avaliação é essencial à educação. Inerente e indissociável enquanto concebida como problematização, questionamento, reflexão sobre a ação" (Hoffman, 2011, p. 15) seria o começo para que as mudanças nos paradigmas que comprometem o fazer avaliativo aconteçam. Afinal, tendo acesso à concepção de que a avaliação da aprendizagem não é apenas classificatória ou excludente, mas sim mediadora do ensino e uma forma de acolhimento do estudante, os profissionais da educação tornam-se capazes de repensar suas próprias metodologias e dar início aos próximos passos no caminho rumo à renovação do ato avaliativo na educação brasileira, modificando práticas, variando métodos e, lentamente, incutindo nos discentes essa nova concepção de avaliação. 
Como afirma Hoffman (2011), "uma prática libertadora da avaliação não exige obrigatoriamente uma revolução de métodos e técnicas, mas uma compreensão diferenciada do seu significado, uma consciência crítica de nossas ações" (p. 94). Com isso, a partir das teorias apreendidas pelos professores e do entendimento ampliado mediante $o$ ato de avaliar, a avaliação da aprendizagem se tornaria, enfim, a forma de mediação do professor para com a aquisição do saber do educando, proporcionando acompanhamento valioso de todo o processo de ensino, permitindo diagnósticos e decisões que se dão durante o fazer educativo, não mais no final e apenas com interesse no registro de notas.

\section{Referências}

BONI, Valdete; QUARESMA, Sílvia Jurema. Aprendendo a entrevistar: como fazer entrevistas em Ciências Sociais. Revista Eletrônica dos Pós-Graduandos em Sociologia Política da UFSC, Santa Catarina, v. 2, n. 1, 2005, p. 68-80.

CARMINATTI, Simone Soares Haas; BORGES, Martha Kaschny. Perspectivas da avaliação da aprendizagem na contemporaneidade. Estudos em Avaliação Educacional, São Paulo, v. 23, n. 52, 2012, p. 160-178.

FIDALGO, Sueli Salles. A avaliação na escola: um histórico de exclusão social-escolar ou uma proposta sociocultural para a inclusão? Revista Brasileira de Linguística Aplicada, Belo Horizonte, v. 6, n. 2, 2006, p. 19-21.

HOFFMAN, Jussara Maria Lerch. Avaliação mito e desafio: uma perspectiva construtivista. Porto Alegre: Mediação, 2011.

LUCKESI, Cipriano Carlos. O que é mesmo o ato de avaliar a aprendizagem? Revista Pátio, São Paulo, v. 3, n. 12, 2000, p. 1-15.

SEVERINO, Antônio Joaquim. Metodologia do trabalho científico. São Paulo: Cortez, 2007.

Izadora Pedruzzi é estudante no curso de Letras com habilitação em Português no Instituto Federal do Espírito Santo.

Orcid: https://orcid.org/0000-0003-3349-9138.

Endereço: Zona rural, s/n - 29295-000 - Vargem Alta - ES - Brasil.

E-mail: izapedruzzi@hotmail.com.

Karine Silveira é professora no Instituto Federal do Espírito Santo.

Orcid: https://orcid.org/0000-0003-3524-6222.

Endereço: Rua Tiradentes, 45 - 29375-000 - venda Nova do Imigrante - ES - Brasil.

E-mail: karine.silveira@ifes.edu.br.

Recebido em 25 de setembro de 2020.

Aceito em 6 de dezembro de 2020.

(c) (1) $(9)$

Regae: Rev. Gest. Aval. Educ.

Santa Maria

v. 10

ก. 19

e55358, p. 1-11

2021 